\title{
Otonom Araçların Otomotiv Sektörüne Etkileri ve Beraberinde Getirdiği Yenilikler
}

\author{
Erkut Yiğit $^{*}$, A.Erdem Öner ${ }^{2}$, Orçun Yöntem ${ }^{3}$ \\ ${ }^{1}$ Toyotetsu Otomotiv Parçaları San. Ve Tic. A.Ș. AR-GE Merkezi, Kocaeli, Türkiye (ORCID: 0000-0001-8912-7267) \\ 2 Toyotetsu Otomotiv Parçaları San. Ve Tic. A.Ş. AR-GE Merkezi, Kocaeli, Türkiye (ORCID: 0000-0002-3865-7054) \\ ${ }^{3}$ Toyotetsu Otomotiv Parçaları San. Ve Tic. A.Ş. AR-GE Merkezi, Kocaeli, Türkiye (ORCID: 0000-0001-7149-9169)
}

(International Symposium on Multidisciplinary Studies and Innovative Technologies (ISMSIT) 2020 - 22-24 Ekim 2020)

(DOI: $10.31590 /$ ejosat.820722)

ATIF/REFERENCE: Yiğit, E., \& Öner, A. E., \&Yöntem, O. (2020). Otonom Araçların Otomotiv Sektörüne Etkileri ve Beraberinde Getirdiği Yenilikler. Avrupa Bilim ve Teknoloji Dergisi, (Özel Sayı), 181-186.

\section{$\ddot{O} z$}

Günümüzde neredeyse tüm otomobil üreticileri, elektronik ve bilişim sektöründen tanınmış birçok şirket sürücüsüz otomobiller için çalışmalar yürütmektedir. Otomobillerde otonom sürüş işlevlerinin tanıtımları yapılmakta, bu teknolojinin insanlar ve çevre için potansiyelleri, faydaları ve risklerini yoğun bir şekilde tartı̧ılmaktadır. Sürüş yardımı işlevine sahip araçların, hatta yolcu ve eşya taşımacılığına yönelik otonom araçların (AV) günlük trafikte giderek artan bir paya sahip olması beklenmektedir. Gerçek sürücüsüz otomobiller, yapay zekânın otomobili tamamen kendi başına sürdüğü ve sürüş görevi sırasında herhangi bir insan yardımı olmadığ1 araçlardır. Otomotiv Mühendisleri Topluluğu (SAE, Society for Automotive Engineers) otonom araçlar için 0 ila 5. seviye arasında değişen standart (J3016) yayınlamıştır. Seviye "0" otomasyon olmayan basit model araçlara işaret ederken, seviye "5" gerçek bir sürücüsüz otomobili belirtmektedir. Sürücüsüz araç teknolojilerinde hedeflenen, mevcut durumda kullanılan ve insanlar tarafindan yapılan faaliyetlerin devre dışı bırakılması, insanların araç idaresi sırasındaki algılama yeteneklerinin teknoloji vasıtasıyla yapılması, daha az risk taşıyacak şekilde araçların üretilmesi ve yaygınlaştırılmasıdır. Bu araçlar hareket kabiliyetini kullanırken insanların duyu organları yerine geçen, daha az hata yapan, daha kısa zamanda karar verebilen; radar, lidar, kamera, sensör, GPS, bilgisayar ve ileri derecede gelişmiş kontrol sistemleri kullanmaktadır. AV'lerin güvenliği ve konforu artıracağı, trafik sıkışıklığını, kirliliği, yakıt tüketimini azaltacağı ve aynı zamanda engelliler ve yaşlı insanlar için mobilite erişilebilirliğini daha da kolaylaştracağ tahmin edilmektedir. Ayrıca, otonom sürüşün kaza ve çarpışmaların sayısını da azaltacağı öngörülmektedir. Bütün bu veriler otonom araçların önümüzdeki yıllara damga vuracak teknolojiler arasında yer alacağını göstermektedir.

\section{The Effects of Autonomous Vehicles on the Automotive Sector and Innovations}

\begin{abstract}
Today, almost all automobile manufacturers, many well-known companies from the electronics and information sector are working for driverless cars. Autonomous driving functions are promoted in automobiles, and the potential, benefits and risks of this technology for people and the environment are discussed extensively. It is expected that vehicles with driving assistance functions and even autonomous vehicles (AV) for passenger and goods transportation will have an increasing share in daily traffic. Real driverless cars are vehicles where the artificial intelligence drives the car completely on its own and there is no human assistance during the driving mission. The Society of Automotive Engineers (SAE) has published a standard for autonomous vehicles ranging from level 0 to level 5 (J3016). Level "0" refers to the base model vehicles without automation, while level "5" refers to a true driverless car. The aim of driverless vehicle technologies is to disable the activities that are currently used and carried out by people, to make people's perception skills during vehicle management through technology, to produce and spread vehicles with less risk. These tools replace
\end{abstract}

\footnotetext{
* Sorumlu Yazar: Toyotetsu Otomotiv Parçaları San. Ve Tic. A.Ş. AR-GE Merkezi, Kocaeli, Türkiye, ORCID: 0000-0001-8912-7267, yigite@ toyotetsu.com.tr
} 
the sensory organs of people while using their mobility, making less mistakes, making decisions in a shorter time; it uses radar, lidar, camera, sensor, GPS, computer and advanced control systems. It is predicted that AVs will increase safety and comfort, reduce traffic congestion, pollution, fuel consumption, and also facilitate mobility accessibility for disabled people and older people. In addition, it is predicted that autonomous driving will reduce the number of accidents and collisions. All these data show that autonomous vehicles will be among the technologies that will mark the coming years.

Keywords: Autonomous Vehicles, Self-Driving Cars, Mobility, V2V Communication, Artificial Intelligence.

\section{Giriş}

Dünya; dijital, fiziksel ve biyolojik dünyaları birleştiren Dördüncü Sanayi Devrimine tanıklık etmektedir (Cohen ve Hopkins, 2019). Bu çağın yapay zekâ (AI), robotik, kuantum hesaplama, nesnelerin interneti (IoT) ve beşinci nesil kablosuz teknolojiler (5G) gibi gelişmiş teknolojilerde öne çıkacağı savunulmaktadır. Öte yandan, iklim değişikliği, nüfus artışı, ulaşım, uluslararası güvenlik sorunları ve küreselleşme, gelecekteki kentsel gelişim için temel zorluk olarak görünmektedir. Bu nedenle, gelişen teknolojilerin ve ihtiyaçların doğru bir şekilde bir araya getirilmesi, gelecekteki şehir hedeflerine ulaşmamızı sağlayacaktır (Wikipedia, 2020).

Dijital ve fiziksel dünyaları birleştirmenin en önemli uygulaması olan otonom araçlar yeni ulaşım konseptlerine ve firsatlarına yol açacağı gibi, ulaşım sistemi kapasitesini ve verimliliğini de artıracaktır. Bu teknolojiler, ulaşım altyapısını kökten değiştirecek ve gelecekteki planlamayı etkileyecektir. AV'lerin gelecekteki akıllı şehirlerde benimsenmesi birçok avantaj sunmaktadır. Bununla birlikte, mevcut literatürün analizinden, birçok akademisyenin güvenlikle ilgili kaygıları olduğu da görülmektedir. AV'lerin sürüş sistemlerinin havacılık standartları kadar sağlam olması gerektiği savunulmaktadır (Kaur ve Rampersad, 2018). Otonom araçların nasıl performans göstereceğini ve davrandığını anlamak için farklı otomasyon seviyeleri vardır. Araçların sağladığı yardım düzeyini ne kadar çok bilgisayar yapıyorsa ve işlev ne kadar çoksa, o kadar otomatikleştirilmiş düzey yükselmektedir.

AV'lerin güvenliği ve konforu artıracağı; trafik sıkışıklığını, kirliliği, yakıt tüketimini azaltacağı ve aynı zamanda engelliler ve yaşlı insanlar için mobilite erişilebilirliğini daha da kolaylaştıracağı tahmin edilmektedir. Ayrıca otonom sürüşün, kaza ve çarpışmaların sayısını azaltacağı öngörülmektedir (Mordue ve ark., 2020). İnternetin ortaya çıkmasından bu yana AV'lerin toplumlarda ve şehirlerde gerçekleşecek en önemli değişim ve geçiş olacağı savunulmaktadır.

Bu makalede 2. bölümde otonom sürüş seviyelerinden bahsedilmekte, 3. bölümde otonom araçlarda kullanılan teknolojilere değinilmektedir. 4. bölümde otonom araç geliştiren şirketler tanıtılmakta ve 5. bölümde otonom araç geliştirmenin zorlukları anlatılmaktadır. Son olarak, 6. bölümde temel bulgular özetlenmiştir.

\section{Otonom Sürüş Seviyeleri}

Otomotiv Mühendisleri Derneği (SAE), bir aracın kendi kendine sürüş yeteneklerine sahip olma derecesini değerlendirmek için altı seviye sunmuştur. SAE, "Karayolu Motorlu Taşıtlar için Sürüş Otomasyon Sistemlerine İlişkin Terimlerin Sınıflandırması ve Tanımları" standardını ilk kez 2014 yılında açıklamış ve son güncellemesini 2018 (J3016_201806) yılında yapmıştır. Bu standart araç otonomisini değerlendirmenin en yaygın kabul gören yöntemi haline gelmiştir. SAE standardına göre, farklı otonom sürüş seviyeleri vardır. Şekil 1'de görüldüğü üzere Seviye "0", bir sürücü tarafından tamamen kontrol edilen eski model araçları temsil etmektedir. SAE seviyesinin yükselmesiyle, otomatik sürüş fonksiyonlarının payı da artmaktadır.

Seviye "1" ve "2", belirli trafik durumlarında şoförü destekleyen sürüş yardımını içermektedir (Örn. otomatik hız sabitleyici, şerit asistan1, otoyol asistanı). Bu teknoloji seviyelerinde, araç sürücüsünün müdahaleleri gerçekleştirebilmek için sürüş durumlarına sürekli olarak hâkim olması gerekmektedir.

Seviye "3" ten itibaren, araç belirli trafik koşullarında kontrolü ele almaktadır (Örn. otoyol şoförü veya trafik sıkışıklığı asistanı). Bu seviyede sürücü araçta okuma, yazma veya dinlenme gibi davranışlarda bulunabilir ancak "3" seviyesinin önemli bir sorunu, otomatik fonksiyonlar bozulursa veya araç karmaşık trafik durumlarıyla başa çıkamazsa sürücünün kontrolü ele alması gerektiğidir.

Seviye "4" de, tam otomatik fonksiyonlar, hiç bir insan müdahalesine gerek kalmadan sürüş kontrolünün gerekli tüm işlemlerini sağlar. Sistem yalnızca belirli ortamlar ve belirli koşullar altında çalışabilir. Bu durum, yağmur yağmaya başladığında veya başka bir şehire gitmek istendiğinde, otonom aracın gidemeyeceği anlamına gelmektedir. Sürücünün, sistem işlevlerinin bozulması veya kişisel isteği ile ele alma ve aracı elle yönlendirme imkânı vardır, ancak genel olarak otomobil kendi kendine sürüşü gerçekleştirebilir.

Son olarak seviye "5", artık insan etkileşimine ihtiyaç duymayan tam otonom aracı temsil eder. Bu seviyede araçlar, yolcuları veya eşyaları bağımsız olarak taşıyan robotlardır. Seviye 4 ve Seviye 5 dâhil standardın tüm seviyeleri yalnızca karayolu sürüşü için geçerlidir ve bu nedenle, arazi sürüşü standart tarafından bir gereklilik değildir.

Günümüzde popüler olan Tesla model araçlar seviye 2 olarak kabul edilir ve AutoPilot'un genişletilmesiyle kademeli olarak Seviye 3'e yaklaşmaktadır. Seviye 3'e ulaşmak için, şirketler son derece farklı yaklaşımlar benimsemektedir. Örneğin, Seviye 3 yelpazesinin bir ucunda Toyota'nın Koruyucu (Guardian) sistemi bulunur. Burada, normal durumlarda sürücü aracın birincil kontrolünü elinde tutar ve sistem olası bir tehlike tespit ederse otomatik olarak eylemi gerçekleştirir. Toyota 5. Seviye tam otonom araç teknolojisini sağlayabilmek amacıyla Şoför (Chauffeur) projesini de yürütmektedir. Seviye 3 için Audi tarafından sunulan bir diğer sistemde; bölünmüş otoyollarda ve yavaş akan trafikte sürücünün otonom sürüş sistemini etkinleştirmesine ve ellerini direksiyondan çekmesine olanak tanır. Bu nedenle, Seviye 3 ve üzeri sistemler geliştikçe, otonom araç karar verme sürecini yönetmek için protokoller ve standartlar geliştirme ihtiyacı artacaktır. (Eliot,2019). 


\section{SAE OTONOM ARAÇ SEVIYELERI}


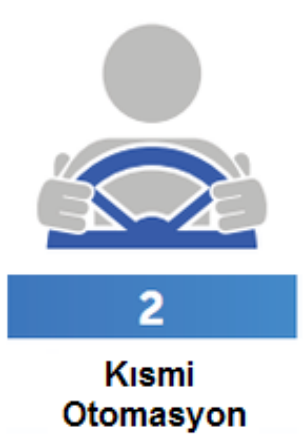

Otomasyon
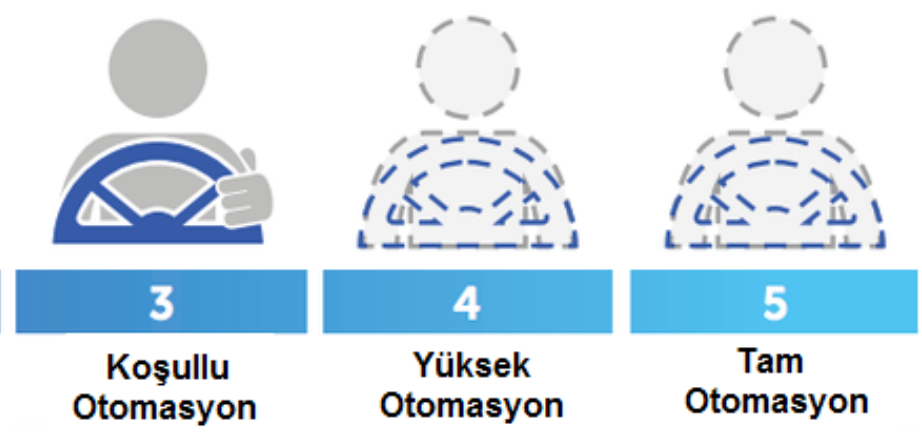

Şekil 1: Otonom Sürüş Seviyeleri [SAE]

2017 y1lında, önde gelen firmalar 2020'lerin başlarında Seviye 4 yeteneklerine erişmeyi tahmin etmekteydi. Son zamanlarda bu haberlere büyük ölçüde güven azalmıştır. Bazı önde gelen şirketler, 2020'lerin başından ortasına kadar Seviye 4 özellikli araçlar için orta ölçekli tahminler sunmaya devam ederken, diğer otomobil üreticilerinin tahminleri, bu tür yeteneklerle donatılacak araçlara ilişkin olumsuzdur. Her koşulda çalışabilen tam otonom araç hakkındaki tahminler önemli ölçüde henüz belirsizdir. Buna rağmen bazı üreticiler yakın gelecekte kablosuz güncelleme yoluyla tam otonom sürüş yeteneklerini araç yazılımlarına ekleyeceğini iddia etmektedir.

\section{Otonom Araçlarda Kullanılan Teknolojiler}

Otonom araç seviyesine ulaşabilmek için otomobil üreticileri tarafindan ara teknolojiler üretilmeye devam edilmektedir. Her bir ara teknoloji bizleri sonuca daha da yaklaştırmaktadır. Kullanılan ara teknolojiler; fren kilitlemeyi önleyen sistem (Anti-Lock Braking Systems (ABS)), hız kontrol sistemi (Cruise Control), park etme sırasında yardımcı olan park sensörü (parking sensors), otomatik acil fren destek sistemi (automatic emergency braking), şerit takip sistemi (lane departure warning), elektronik denge kontrol sistemi, (electronic stability control) ve benzeri sistemlerdir (Yetim, 2016).

Şekil 2'de çevre ve nesne tanıma için araç içi sensör sistemlerine uygulanabilen teknolojiler gösterilmektedir. Yıllardan beri çok yaygın olan, yaklaşık 2 metre çalışma aralığına sahip ultrasonik sensörler otopark asistanı işlevleri için kullanılmıştır. Görüntü işleme teknolojisiyle birlikte kamera sistemleri de devreye girmiştir. Bu teknoloji, nesne tanımlama için uygun maliyetli olmasına rağmen algılama kalitesi büyük ölçüde çevresel koşullara bağlıdır (Örn. hava koşulları ve 1şık yansıması). Kullanılan gece görüş teknolojisi ise, kızılötesi kamera sistemlerine dayanmaktadır. Radar sensörler, 250 metreye kadar uzun bir çalışma aralığına sahiptir ve farklı hava koşullarında doğru sonuçlar vermektedir. Uzun menzilli radar sistemleri, yoldaki diğer araçları tanımlamak için otomatik hız sabitleyici işlevlerinde kullanılır. 30 ilâ 150 metre menzile sahip ön ve arka orta menzilli radar sistemleri, acil durum fren asistanlarında ve yüksek yol asistanlarında (otomatikleştirilmiş sollama işlemleri) kullanılmaktadır. Son olarak, yüksek maliyetli olan lazer tarayıcı sistemlerde (LIDAR) doğruluk payı oldukça yüksektir. LIDAR, dönen lazer 1şı darbelerinin kullanılmasıyla, 100 metreden fazla bir çalışma menzilini tarayarak çevredeki ortamın ayrıntılı üç boyutlu haritalarını oluşturabilir (Hirz ve Walzel, 2018). Kamera tabanlı teknolojiler, nesne yüzeyi ve görünüm özellikleri hakkında ayrıntılı bilgi sağlar, ancak kötü hava ve düşük ış1k koşullarında konum, hız ve yörünge belirleme performansı kısıtlıdır. Radar sistemleri, kötü çevre koşulları altında bile nesne konumu ve hızı hakkında güvenilir bilgi sağlar, ancak uygulanan teknoloji nedeniyle nesne türü, geometri ve yüzey bilgileri hakkında veri sağlayamazlar. Son olarak lazer sensörler, hareketli nesnelerin mesafesi, hızı ve yörüngesi hakkında ayrıntılı bilgilerin yanı sıra çevrenin ve çevredeki öğelerin ayrıntılı geometri verilerini sağlayabilir. Tek olumsuz yanı, lazer sensörler yüzeylerdeki bilgileri tanıyamamaktadır (Örn. trafik işaretleri üzerindeki uyarılar). Otonom araçlar için nesne tanıma teknolojilerindeki eğilim, kamera tabanlı teknolojileri radar veya lazer sensörle birleştiren yapı yönünde ilerlemektedir. Böylece her bir teknolojinin avantajları etkili bir şekilde kullanılabilmektedir.

Bahsedilen sensör teknolojileri, uygulama alanlarına göre kullanılmakta ve küresel konumlandırma sistemleri (GPS) ile birleştirilmektedir. Harici bilgiler araç ile haberleşen (V2X, Vehicle to everything ) diğer sistemler tarafından alınmaktadır (Örn. 3B haritalar, trafik durumları, yol üzerindeki inşaat alanları veya tehlikeli yol ve hava durumları). Sensörler ile konumlandırma ve haberleşme sistemleri tarafından iletilen tüm verilerin birleşimiyle veriler arasındaki ilişki yorumlanarak gerçek trafik durumu tahmini yapilabilmektedir.

Bazı otomobil üreticileri daha pahalı olduğu ve kameradan daha etkili olmadığına inandıkları için araçlarına LiDAR sistemleri eklemekten çekinmekte, ancak yine de kameralarının etkinliğini doğrulamak için LiDAR'ı kullanmaktadır. Bununla birlikte bazı üreticiler de otonom araçlarındaki sensör düzenlemelerinin temel bir parçası olarak bir kamera ve LiDAR kombinasyonuna 
güvenmektedir.

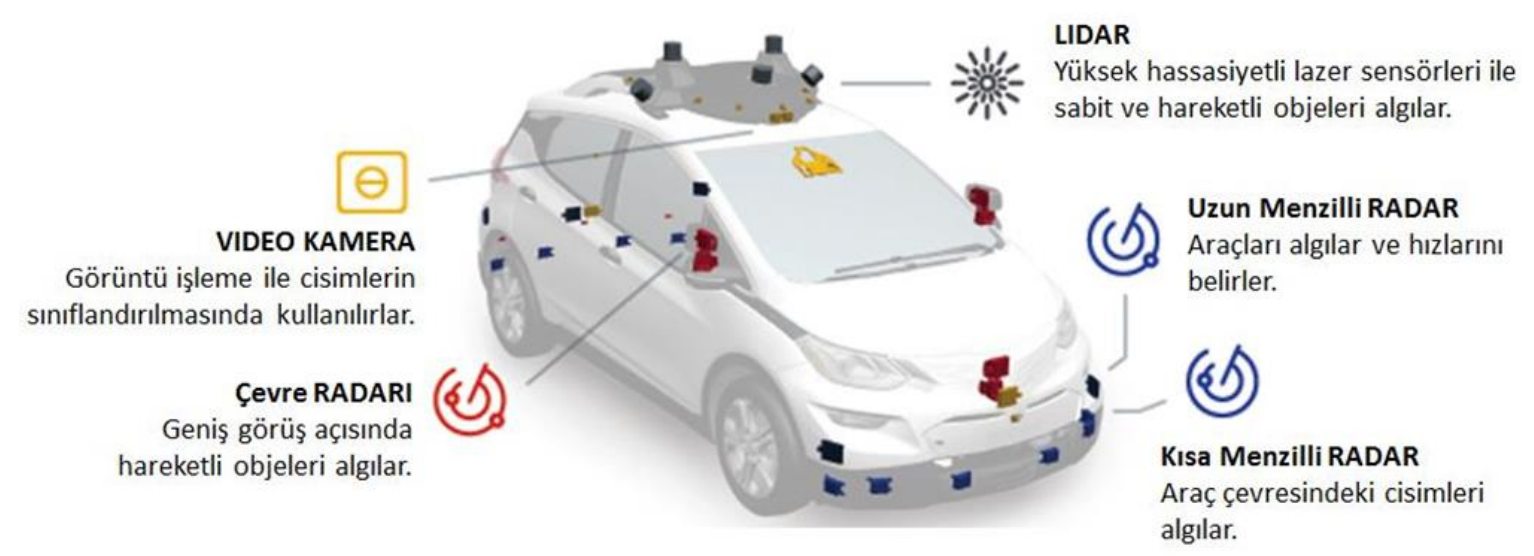

Şekil 2: Otonom Araçlarda Kullanılan Sensörler (GM 2018 Self Driving Safety Report)

\section{Otonom Araç Geliştiren Şirketler}

Günümüzde otonom araçların geliştirilmesi konusunda çalışma yapan ve test sürüşlerini devam ettiren birçok şirket vardır. Bu şirketlerin isimleri ve yürüttükleri projeler ise; Toyota'nın "Guardian" ve "Chauffeur", Audi’nin "Piloted Driving", BMW'nin "Electronic co-pilot system", Ford'un "Automated Fusion Hybrid", General Motor’un "Super Cruise" ve "Chevy EN-V", Lexus'un "Advanced Active Safety Research Vehicle", Mercedes-Benz'in "Mercedes-Benz Intelligent Drive", Nissan'ın "Autonmous Drive", Tesla'nın "Auto Pilot", Volkswagen'in "Temporary Auto Pilot", Volvo'nun "Drive Me", Google'nin "Driverless Car Project" ve Bosch'un "Autonomous Vehicle" projeleridir. Mercedes-Benz firması, diğer firmalardan farklı şekilde çalışacak otonom araçlarla birlikte Uber yolcu taşımacılığı hizmetleri gibi bir kısım hizmetleri de vermeyi hedeflemektedir. Car2go ve MyTaxi bu projelerin başlıcalarındandır. Uber firması da kendilerine ait otonom araçların testlerini 2015 yılı başından itibaren yapmaya başlamıştır. Otonom araçlarla ilgili çalışma yapan şirketlerin çoğunun $\mathrm{ABD}$ ve Almanya patentli olduğu görülmektedir. Bu durum ilerleyen aşamalarda otonom araçların üretimi konusunda bir tekelin oluşabileceğinin de göstergesidir (Webb ve ark., 2019).

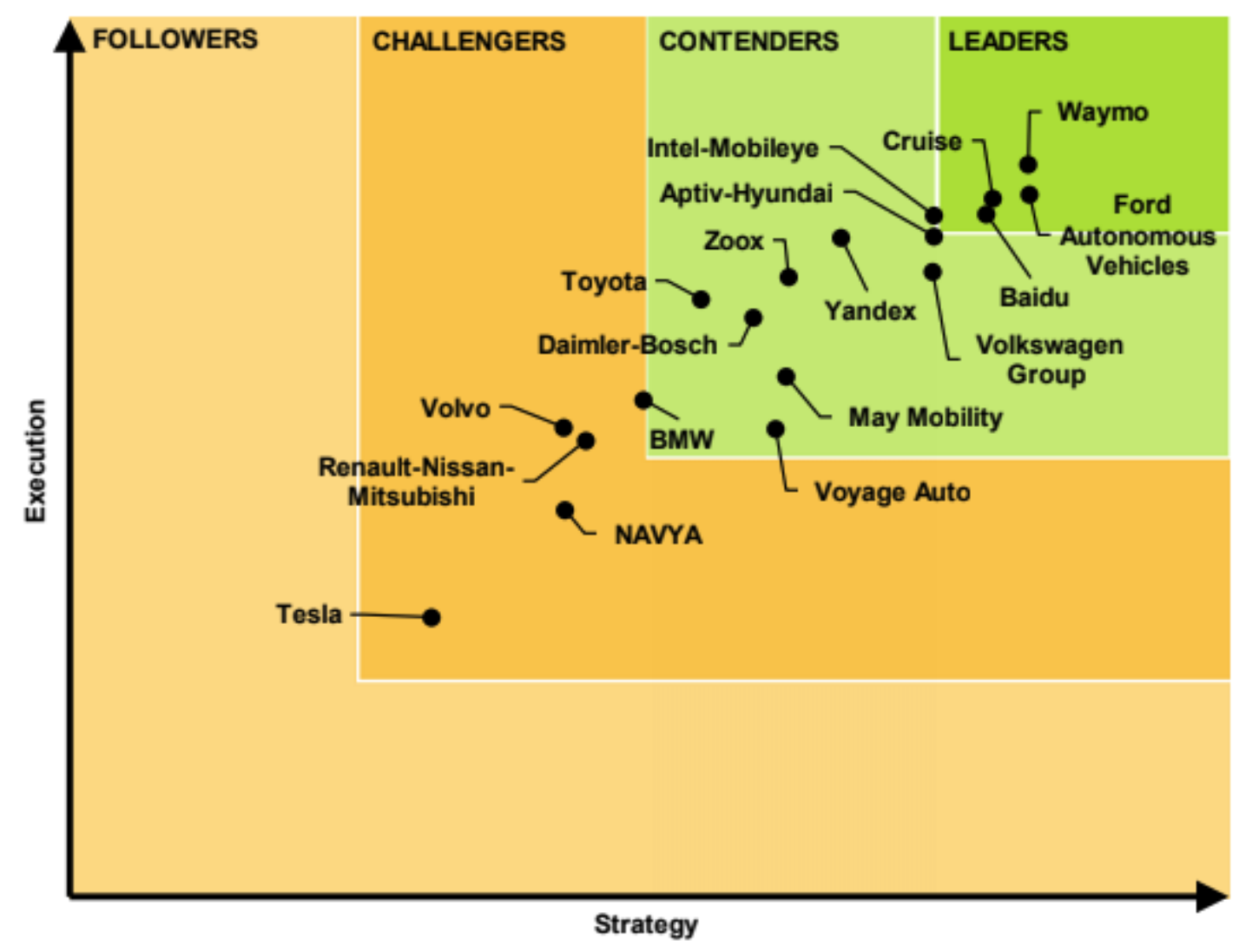

Şekil 3: Navigant Research Araştırması (Mart 2020 ) 
Navigant Research şirketi her yıl, otonom araç teknolojisi için çalışan önde gelen şirketleri içeren otomatik sürüş liderlik tablosu yayınlamaktadır. Yayınlanan bu yılki liste, 18 şirketi teknolojilerine, vizyonlarına, pazara açılma stratejilerine, ürünlerine, ortaklıklarına ve diğer birçok özelliğine göre sıralamıştır. Araştırmaya göre "Liderler" kategorisinde Google'ın yan şirketi Waymo, Ford'un AV, General Motors'un Cruise, Çin'in Baidu ve Intel-Mobileye şirketleri görülmektedir. Bir sonraki kategori olan "Yarışmacılar" listesinde, Daimler (Bosch ortağıyla birlikte), Hyundai (ortağı Aptiv ile birlikte), Toyota, Volkswagen, Zoox, May Mobility ve ilk kez ortaya çıkan Rusya'nın Yandex'i gibi şirketler yer almaktadır. Sondan bir önceki "Meydan Okuyanlar" kategorisinde ise, Volvo, Renault-Nissan-Mitsubishi ortaklığı gibi şirketler görünmektedir. Aynı zamanda Tesla da bu kategoriye girmiştir. "Tesla, 2020'nin sonuna kadar yolda bir milyon robotaksi özellikli araç bulundurmak" (Tesla, 2019) da dâhil olmak üzere iddialı sözler vermeye devam etmektedir. Bazı büyük şirketler bu yıl Navigant'ın liderlik tablosuna girememiştir. Navigant'a göre Apple, "herhangi bir ticarileştirme planının net bir görünümünü" sunmadığı için sıralamada düşmüştür. Uber, araçlarından biri bir yaya ile ölümcül bir çarpışmaya karıştıktan sonra, AV çabalarını yeniden hızlandırmaya çalışmaktadır. Uber'in rakibi Lyft firması Magna ile kurdukları ortaklığı sonlandırma kararı almış (Ocak, 2020) ve son aylarda pek ilerleme kaydetmemiştir. Gelişmelere bakıldığında şirketlerin otonom araç konusundaki ilerlemesini ölçmek zordur. Kesin olarak bildiğimiz tek şey, şuan için tam otonom araç teknolojisine henüz ulaşamadığımızdır.

\section{Otonom Araçlardaki Zorluklar}

Bir otomobil üreticisinin, araçlarından birinin belirli bir SAE kabiliyetine sahip olduğunu beyan etmesi mümkün olsa da, iddia edilen kabiliyetlerin doğruluğunu yargılamak için evrensel bir standart yoktur. Sürücülerin birincil önceliği kendini korumaktır. Bu nedenle sürücüler kendi güvenliklerini korumaya öncelik veren kararlar almaktadır (Awad ve ark., 2020).

Yeni bir teknolojinin benimsenmesi her zaman insanların zihniyetinden ve tutumundan etkilenmiştir. AV'ler çeşitli faydalar sağlayacağından, birkaç potansiyel riskle de ilişkilendirilebilir. Örneğin, ulaşım sisteminin dijitalleştirilmesi, sistemi korsanlığa karşı savunmasız bırakabilir. Ayrıca, AV'lerin sistem arızasına maruz kalabileceği de iddia edilmektedir. AV'lere bağlanabilecek diğer bir tehlike, güvenilmeyen bir ağ üzerinden yapılan kötü niyetli siber saldırılardır (Anania ve ark., 2018).

Pek çok kişi otonom araçlarla birlikte kazaların tamamen ortadan kalkacağını savunurken, otonom araç segmentinin en güçlü savunucuları, bu ideale ulaşma yolunun sorunlu olacağını ve ekipman arızalarının buna sebep olacağını belirtmektedir (Morduea ve ark., 2019). Toplumda otonom araçlarla ilgili birçok soru işareti bulunmaktadır. Araçlar arasında ne kadar veri alışverişi yapılmalıdır? $\mathrm{Bu}$ araçlara rehberlik eden algoritmalar, sürücülerin güvenliğini sağlarken yayalara, gençlere, yaşlılara, iyi sürücülere, kötülere, kırmızı 1şıkta yürüyen yayalara, kurallara uyan sürücülere, daha az veya daha yüksek güvenlik dereceli araçlara öncelik vermeli mi? Daha az yolcuya sahip araçlar, daha fazla yolcuya sahip olanlara feda edilmeli mi? Bir sonucun diğerinden daha az veya daha fazla "tehlikeli" olup olmadığını belirlemek için hangi standartlar uygulanmaktadır? Bu çukur o duvardan daha mı az tehlikeli? Kim için tehlikeli? Bu faktörler, çeşitli paydaşların verdiği kararları nasıl etkileyecek? Örneğin, araçlara birkaç kişi için birkaç kişiyi feda etmeleri talimatı verilmişse, araçlardaki yolcu sayısı hakkındaki kararları nasıl etkiler? Programcılar, düzenleyiciler veya yasal makamlar sahte bilgileri belirleyebilecek mi? Araçlara programlanan algoritmalar, bugün "daha güvenli" olarak kâbul edilen araçları gelecekte "daha az güvenli" hale mi getirecek? Bu soru işaretlerinin çoğu hala belirsizliğini korumaktadır. (Bcg, 2017).

Avrupa, Japonya ve Güney Kore, öncelikle Birleşmiş Milletler tarafindan ifade edilen standartlara bağliyken, ABD, Kanada, Hindistan ve Çin gibi diğer büyük otomotiv pazarları kendi kurallarını takip etmektedir. Bir kesişme meydana gelse de, bunun etkisi, Avrupalı otomobil üreticilerinin araçların ABD, Kanada, Hindistan ve Çin pazarlarına erişim sağlamak için ayarlamaları gerektiğidir. Üst kademe otonom araç teknolojisi tanıtıldıkça, düzenleyici standartların karmaşıklığı da artacaktır. (Daniel ve ark.,2015) Örneğin, farklı ülkeler için programlanmış otonom araçlar arasındaki uyumsuz standartlar, orijinal olarak ABD'de satılan araçların Kanada karayollarında kullanılamamasına veya tam tersine neden olabilir. Tamamen otonom (SAE Seviye 5) araçların ne zaman mevcut olacağına dair tahminler kesin olmamakla birlikte, otomobil üreticileri yüksek seviyeli otonomiye (SAE Seviye 4) sahip araçların 2020'lerin başından ortalarına kadar piyasaya sürüleceğini tahmin etmektedir (Adnan ve ark.,2018).4

\section{Sonuç}

AV'lerin şehirlerimizde neden olabileceği etkileri ve değişiklikleri anlamak ve değerlendirmek için, öncelikle bir AV'nin nasıl çalışı̆ı̆ını ve "otonom araç sistemi mimarisi" olarak adlandırılan mekanizmayı anlamak gerekmektedir. İkinci olarak, bu teknolojilerin benimsenmesini kısıtlayan çeşitli engelleri belirlemek ve çözümlere odaklanılması gerekmektedir. AV'lerin sorunsuz performansını ve güvenliğini sağlayan gerekli altyapılar oluşturulmalıdır. Öncelikle sürücünün becerisine veya durumuna bakılmaksızın, çarpışmaya neden olmayan bir otomobil üretme hedefi ile otomobillerin güvenliği artırılmalıdır. Yaşlılar, özel ihtiyaçları olan insanlar veya bir şekilde araba kullanmakta zorluk çekenlerin erişimini artırmaya yönelik çalışmalara önem verilmelidir. Otonom araçların ulaşım, toplu taşıma ve lojistik sektöründe kullanımı kaçınılmaz olacaktır. Tüm bu gelişmeler ışığında yakın gelecekte sürücüsü olmayan araçlar vasıtası ile seyahat etmek mümkün olacak, ulaşım sektöründe köklü değişimler yaşanacak ve insanlar daha kaliteli yaşam imkânı sunan akıllı şehirlerde yaşamayı tercih edeceklerdir. 2030 yılında dünya nüfusunun \%60'ının büyük şehirlerde yaşayacağı öngörülmektedir. Otonomluk sadece kullandığımız araçları değil yaşadığımız mekânları da değiştirecektir. Geleceği düşünürken bir noktadan diğerine gidebilmeyi yani mobiliteyi yeniden tanımlamak gerekmektedir. Gelecekteki akıllı şehirlerde insan odaklı iyi bir mobilite tasarımı yapılırsa yaşam kalitemiz daha da artacaktır. Otopark kullanımı da azalacağından daha fazla yeşillik ve yaşama alanları oluşturulabilecektir. Elektrikli ve otonom otomobiller ile daha temiz ve güvenli yolculuklar gerçekleştirilebilecektir. 


\section{Kaynakça}

S.A. Cohen, D. Hopkins, Autonomous vehicles and the future of urban tourism, Ann. Tour. Res. 74 (2019) 33-42.

Autonomous Car, https://en.wikipedia.org/wiki/Autonomous_car, (20.09.2020).

K. Kaur, G. Rampersad, Trust in driverless cars: Investigating key factors influ- encing the adoption of driverless cars, J. Eng. Technol. Manag. 48 (2018) 87-96.

Mordue et al., G. Mordue, A. Yeung, F. Wu "The looming challenges of regulating high level autonomous vehicles" Transportation Research Part A: Policy and Practice, 132 (2020), pp. 174-187.

SAE International standard J3016: Taxonomy and Definitions for Terms Related to Driving Automation Systems for On-Road Motor Vehicles J3016 (2018) < https://www.sae.org/standards/content/j3016_201806/> accessed 19 Sept 2020.

L.Eliot, (20.12.2019), "Explaining Level 4 And Level 5 Of Self-Driving Cars In Plain English", https://www.forbes.com/sites/lanceeliot/2019/12/20/explaining-level-4-and-level-5-of-self-driving-cars-in-plain-english/

L.Eliot, (2018). "Reframing AI Levels for Self Driving Cars: Bifurcation of Autonomy", https://www.aitrends.com/selfdrivingcars/reframing-ai-levels-for-self-driving-cars-bifurcation-of-autonomy/

Yetim S. (2016). Sürücüsüz Araçlar ve Getirdiği / Getireceği Hukuki Sorunlar, 2016/1 Ankara Barosu Dergisi.

M. Hirz and B. Walzel, "Sensor and object recognition technologies for self-driving cars," Computer-Aided Design and Applications, pp. 1-8, January 2018.

J. Webb, C. Wilson, T. Kularatne, Will people accept shared autonomous electric vehicles? A survey before and after receipt of the costs and benefits, Econ. Anal. Policy. 61 (2019) 118-135,

Awad, E., Dsouza, S., Kim, R., Schulz, J., Henrich, J., Shariff, A., Rahwan, I. (2020). Reply to: life and death decisions of autonomous vehicles. Nature, 579 (7797), E3-E5.

Morduea. G, Yeung A., Wu. F, (2019), The looming challenges of regulating high level autonomous, Transportation Research Part A 132 (2020) 174-187.

E.C. Anania, S. Rice, N.W. Walters, M. Pierce, S.R. Winter, M.N. Mil- ner, The effects of positive and negative information on consumers' will- ingness to ride in a driverless vehicle, Transp. Policy. 72 (2018) 218-224.

Daniel J. Fagnant and Kara Kockelman. (2015) "Preparing a nation for autonomous vehicles: opportunities, barriers and policy recommendations." Transportation Research Part A: Policy and Practice 77: 167-181.

By 2030, 25\% of Miles Driven in US Could Be in Shared Self-Driving Electric Cars, https://www.bcg.com/press/10april2017-futureautonomous-electric-vehicles/, (10.05.2017).

Adnan, N., Nordin, S. M., bin Bahruddin, M. A., \& Ali, M. (2018). How trust can drive forward the user acceptance to the technology? In-vehicle technology for autonomous vehicle. Transportation research part A: policy and practice, 118, 819-836. 